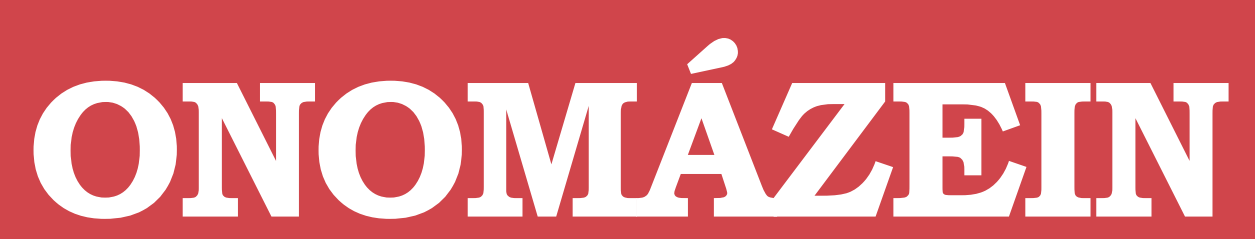

Revista de lingüística, filología y traducción
PONTIFICIA UNIVERSIDAD

\title{
Herencia e innovación en el Diccionario militar portátil (1822) de Fernández Mancheño ${ }^{1}$
}

Inheritance and innovation in the Diccionario militar portátil (1822) of Fernandez Mancheño

\section{Marta Sánchez Orense \\ Universidad de Murcia \\ España}

\section{(c) $(i) ~ \bigodot$}

Marta Sánchez Orense: Departamento de Lengua Española y Lingüística General, Facultad de Letras, Universidad de Murcia, España. | Correo electrónico: m.sanchezorense@um.es 


\section{Resumen}

En el presente trabajo nos proponemos rastrear la huella del Diccionario militar (1749) de Raimundo Sanz, el primer representante en lengua española de esta variedad lexicográfica especial, en el Diccionario militar portátil (1822) de José Fernández Mancheño, compuesto en la centuria siguiente, con el fin de calibrar cuánta de su terminología responde más bien a herencias que a la innovación propia. Constituirá igualmente nuestro objetivo verificar las influencias mutuas de tipo semántico, además de las concernientes a la marcación empleada para la restricción del uso de los términos. Gracias a nuestro análisis contrastivo, se obtienen varias conclusiones, entre las que destacan, primero, que la innovación en el caso de Fernández Mancheño respecto a su inmediato predecesor consiste, curiosamente, en recurrir a la terminología bélica de épocas pasadas y, segundo, que son la marcación y las definiciones los elementos microestructurales en los que más se aprecia el avance realizado por Fernández Mancheño respecto a Sanz.

Palabras clave: lexicografía; milicia; macroestructura; microestructura.

\section{Abstract}

In this paper we propose to locate the trace of Raimundo Sanz's Diccionario militar (1749) the first example in Spanish language of this special lexicographical variety-in the Diccionario militar portátil (1822) of José Fernández Mancheño, composed in the next century, in order to find out how much of its terminology meets inheritances rather than own innovations. Our objective is also to verify the mutual semantic influences, in addition to those concerning lexicographical marks, which are used to restrict the words. Thanks to our contrastive analysis, several conclusions can be drawed. The most important are, first, that innovation in Fernandez Mancheño with respect to its direct predecessor, curiously, is to have recourse to military terminology of the past and, second, that the marks and the definitions are the microstructural elements where the progress reached by Fernández Mancheño compared to Sanz is more obvious.

Keywords: lexicography; militia; macrostructure; microstructure.

1 Investigación patrocinada por el proyecto de investigación 19296/PI/14 financiado por la Fundación Séneca-Agencia de Ciencia y Tecnología de la Región de Murcia en el marco del PCTIRM 2011-2014. 


\section{Introducción}

Tras la publicación en 1749 del primer diccionario militar del castellano, obra de Raimundo Sanz, el panorama lexicográfico de nuestra lengua experimenta una auténtica eclosión en lo que respecta a la elaboración de glosarios, vocabularios y diccionarios encargados de recopilar y definir los numerosos tecnicismos militares existentes.

Así, en 1791 y 1792 salen a la luz los dos tomos de la Encyclopedia metódica dedicados en exclusiva a la milicia, que, como el Diccionario militar de Sanz, son traducción de una obra francesa - la Encyclopédie méthodique, realizada por Luis Castañón-. El siglo XVIII es también testigo del primer repertorio plurilingüe centrado en la milicia en el que, aparte de otras lenguas, se contempla la española: A pocket vocabulary in six languages, viz. English, German, Dutch, French, Italian and Spanish; containing such words, terms and questions, as are most generally in use, particularly in military service, de James Willson (1974), precursor de una larga lista de diccionarios, en su mayoría bilingües.

Ahora bien, el momento de máximo apogeo en el surgimiento de la lexicografía militar corresponde en realidad al siglo XIX²; así, el Diccionario militar portátil (1822) de José Fernández Mancheño, el Diccionario militar español-francés (1828) de Federico Moretti, el Vocabulario militar (1849) de Luis Corsini, el Diccionario general militar (1857) de Deogracias Hevia, el Diccionario militar (1869) de José Almirante, el Diccionario de ciencias militares (1895-1901) de Rubió y Bellvé y el Diccionario militar (1897) de Nicolás Estévanez son solo algunos de los múltiples ejemplos que podrían citarse a propósito de esta peculiar manifestación decimonónica.

El primero de ellos, el Diccionario militar portátil o recopilación alfabética de todos los términos propios de las ciencias militares, explicación de los empleos de la milicia y

2 Cfr. Gago-Jover (2008) y Gago-Jover (2011). Por otro lado, las razones de la supremacía del siglo XIX en lo que respecta a esta modalidad lexicográfica especializada podrían situarse en los relevantes acontecimientos que fueron sucediéndose tanto en España como en Europa a lo largo de dicha centuria, los cuales lograron ir modificando la mentalidad del militar español: "guerras, expediciones, intervenciones en la política, tensiones internas, motines, pronunciamientos, aplicación de diferentes políticas militares, progresos en el arte de la guerra, revolución de los armamentos, transformaciones técnicas, reformas (proyectadas, frustradas y consumadas), reorganizaciones orgánicas, aparición de entidades civiles militarizadas, cambios administrativos y en la formación académica y cultural militar, aumento de la profesionalidad y del sentido corporativo, influencia castrense exterior, variaciones en su relación con la sociedad y otras propiciaron que la institución militar fuera mudando en el tiempo y que, como consecuencia, la mentalidad de sus componentes no fuera la misma" (Pinto Cebrián, 2013: 195). Dados estos importantes cambios que para el ámbito bélico trajo consigo el siglo XIX, no es de extrañar el interés por dar cuenta de ellos por parte de algunos profesionales en la milicia, ya no solo en obras lexicográficas, sino en cualquier otro tipo de texto. 
sus obligaciones, y de las diferentes especies de tropas, clases distintas de armas antiguas y modernas, máquinas de guerra, etc., etc., es obra del teniente coronel de infantería José Fernández Mancheño, quien tiene el honor de inaugurar nuestra lexicografía militar plenamente original. Es decir, si bien esta peculiar corriente especializada ya había sido iniciada en el siglo anterior por Raimundo Sanz, con la publicación en 1749 de su traducción al castellano del Dictionnaire militaire de Aubert de la Chesnaye-Desbois³, no es hasta este momento cuando el interés por confeccionar repertorios propios y novedosos se hace especialmente patente.

Como ya especificamos en Sánchez Orense (2014: 275-276), el repertorio de Fernández Mancheño consta de una estructura bastante sencilla: tras la portada se halla un breve "Discurso preliminar", al que le sigue la "Explicación de las abreviaturas usadas en esta obra", para a continuación encontrar el cuerpo lexicográfico propiamente dicho, mientras que unas "Adiciones" finales, donde Fernández Mancheño añade algunos términos más, le sirven para cerrar su Diccionario militar portátil.

En esta ocasión, nuestro propósito consiste en rastrear la huella del primer diccionario militar del español, la traducción de Raimundo Sanz, en la obra de Fernández Mancheño, con el fin de calibrar cuánta terminología en él contenida responde más bien a herencias que a la innovación propia. Así, metodológicamente, atenderemos a los aspectos macroestructurales del Diccionario militar portátil en busca de similitudes léxicas con el Diccionario militar de Sanz. Pero, además, constituirá también nuestro objetivo verificar las influencias mutuas de tipo semántico, así como las concernientes a la marcación empleada para la restricción del uso de los términos, para lo cual examinaremos igualmente los contenidos microestructurales.

Comprobaremos, de este modo, cómo el Diccionario militar de Raimundo Sanz se convirtió en el principal referente de Fernández Mancheño, lo cual de cierta manera resulta lógico, pues dichas obras, además de poseer idéntica naturaleza, son las únicas que hasta ese momento se ciñeron a la terminología militar del castellano.

3 El nombre completo de este primer diccionario militar del español es sumamente dilatado, a saber, Diccionario militar, o recolección alphabética de todos los términos propios al Arte de la Guerra. Explicación y práctica de los trabajos que sirven al ataque y defensa de las plazas: Sus ventajas y defectos según sus diferentes situaciones, con un detalle histórico del origen y naturaleza de diferentes especies, tanto de empleos antiguos y modernos como de las armas que se han usado en diferentes tiempos de la monarchía francesa hasta oy. Breve y extracta explicación de la obligación de los oficiales de Infantería, Cavallería, Dragones, Artillería e Ingenieros, sea en guarnición o campaña, según el méthodo presente de hacer la guerra. Para adentrarse en el conocimiento del mismo, con especial atención al método de traducción seguido por Sanz, ya perceptible en el propio título, véanse Sánchez Orense (2013) y Sánchez Orense (2015). 


\section{Aspectos macroestructurales}

Tras un minucioso recuento, confirmamos que el Diccionario militar portátil consta en su lemario de 2995 entradas, de las cuales 91 forman parte de las "Adiciones".

Como puede comprobarse en el siguiente cuadro 4 , este repertorio supone un gran avance respecto a suantecedente, el Diccionario militarde Sanz, en lo que respecta a la macroestructura:

\section{TABLA 1}

Resumen comparativo del número de entradas recogidas por cada letra

\section{LETRA SANZ (1749) FERNÁNDEZ MANCHEÑO (1822)}

\begin{tabular}{ccc}
$A$ & 49 & 275 \\
\hline$B$ & 67 & 114 \\
\hline$C$ & 112 & $703 / 46^{5}$ \\
\hline$D$ & 23 & 178 \\
\hline$E$ & 36 & $175 / 20$ \\
\hline$F$ & 40 & $105 / 6$ \\
\hline$G$ & 23 & 95 \\
\hline$H$ & 8 & $55 / 1$ \\
\hline$I$ & 16 & $62 / 4$ \\
\hline$J$ & 3 & $17 / 3$ \\
\hline$L$ & 15 & 131 \\
\hline$M$ & 41 & 146 \\
\hline$N$ & 5 & 42 \\
\hline$O$ & 20 & $64 / 2$ \\
\hline$P$ & 61 & $274 / 2$ \\
\hline$Q$ & 11 & 14 \\
\hline$R$ & 25 & $91 / 5$ \\
\hline$S$ & 30 & 159 \\
\hline$T$ & 30 & $133 / 2$ \\
\hline
\end{tabular}

4 Sobre algunos detalles de la elaboración de este cuadro, véase Sánchez Orense (2014: 278-279).

5 Cuando se ofrecen dos cifras, como aquí, la segunda se refiere a las "Adiciones". 


\begin{tabular}{lll}
\hline$U$ & $4^{6}$ & 6 \\
\hline$V$ & 7 & 54 \\
\hline$Y$ & 0 & 2 \\
\hline$Z$ & 3 & 9 \\
\hline
\end{tabular}

A propósito de estos datos, debe tenerse en cuenta que, como era habitual entonces, Fernández Mancheño asigna a cada acepción o uso su propio artículo lexicográfico, al igual que procede con las múltiples unidades pluriverbales recogidas.

Asimismo, si bien en principio Fernández Mancheño ofrece ordenados alfabéticamente esos 2995 artículos, no son raras las ocasiones en las que esta disposición resulta alterada, como sucede con los lemas desertor y deserción, los que aparecen tras deshonor en vez de en su lugar correspondiente?.

Pues bien, dado que comparar íntegramente ambas macroestructuras excedería con mucho los límites de este trabajo, nos limitaremos seguidamente a cotejar cuántas de las 112 voces de que consta el diccionario de Sanz bajo la letra C forman realmente parte de la obra lexicográfica de Fernández Mancheño. Igualmente, trataremos de apuntar la procedencia semántica de las múltiples nuevas incorporaciones de este, a la vez que analizaremos, por último, si hay algún vínculo en común entre las que decide desechar.

Respecto a la primera incógnita planteada, aclaramos que son exactamente 90 los lemas de Sanz mantenidos por Fernández Mancheño en su trabajo lexicográfico, siendo, por otro lado, 22 aquellos de los que prescinde.

Entre las 90 coincidencias, anotamos, no obstante, algunas leves modificaciones de uno a otro diccionario, las cuales afectan casi en exclusiva al proceso de lematización. Por ejem-

6 Sanz sitúa en realidad esos cuatro lemas que empiezan por U bajo la $V$ y mezclados con los siete que estrictamente pertenecen a ella. Nosotros hemos decidido ofrecer estas respectivas cifras por separado, entre otras cosas, por seguir la disposición de Fernández Mancheño.

7 También en las "Adiciones" encontramos ejemplos de rupturas de la ordenación, como cuando bajo la letra C Fernández Mancheño coloca las entradas cola de golondrina, cola de trinchera y columna volante o movible antes de canana. En el caso de Sanz, él mismo advierte en su prólogo: "el curioso notará [...] la falta del riguroso orden alphabético, y que solo está dispuesto a la letra inicial” (Sanz, 1749: XVI). De acuerdo con Gago Jover y Tejedo Herrero (2007: X), esta peculiar ordenación seudoalfabética resulta de haber traducido según el orden del original francés: "cuando la entrada en español comienza con la misma letra que la francesa, Sanz la mantiene bajo esa letra. Sin embargo, cuando la entrada en español comienza con letra diferente a la francesa, Sanz la sitúa bajo esta nueva letra -al comienzo de ella si todavía no ha llegado a esta sección en el texto francés, y al final si ya lo ha hecho". 
plo, en el caso de los sustantivos en Raimundo Sanz, ya Gago Jover y Tejedo Herrero (2007: XVII) Ilamaron la atención hacia los frecuentes encabezamientos con voces-guía en plural. En cambio, en Fernández Mancheño es patente el proceso de depuración Ilevado a cabo en este aspecto. Así, son numerosos los ejemplos que a propósito de él pueden citarse, si bien nos limitaremos a mencionar solo los detectados bajo la letra C; con ellos, rápidamente se constata la profunda reflexión que antecede a la labor lexicográfica de Fernández Mancheño, pues la simplificación acometida en estos lemas responde a la inexistencia de razones de peso para el mantenimiento de los mismos en pluralia tantum:

\section{TABLA 2}

De lemas plurales en Sanz a singulares en Fernández Mancheño

\section{SANZ (1749)}

\section{FERNÁNDEZ MANCHEÑO (1822)}

CUREÑAS, para servicio de las piezas de campaña, compuesta de dos tablones (para el de a veinte y quatro), de trece pies y medio de largo y un calibre de gruesso (cinco pulgadas y ocho líneas), quatro teleras, un exe, dos ruedas y su abantrén, que solo sirve para conducirle [...].

CARAVINEROS, eran soldados de a cavallo armados con caravinas, y formavan alguna vez compañías separadas destinadas para guardia de los oficiales generales. Otras veces fueron puestos en regimiento y mandados por el coronel de él; su empleo era apoderarse de los passos y de insultar al enemigo en sus puestos [...].

CASERNAS, son grandes habitaciones distiribuidas en varias divisiones, que sirven para alojar a los soldados y de alivio y descargo a los súbditos. Las casernas o quarteles ordinariamente se construyen entre el rampar y las casas inmediatas de una plaza fuerte [...].

CORACEROS, son soldados de a cavallo armados de corazas, y forman un regimiento. En Alemania ay muchos regimientos de coraceros que están reputados por las mejores tropas imperiales.

CESTONES $^{8}$, son unos cilindros texidos de mimbres o ramas de cinco a seis pies de alto sobre quatro de ancho. Llénanlos de tierra para cubrirse contra el fuego de los enemigos [...].
Cureña. Para las piezas de campaña. Es compuesta de dos tablones; para las de a 24, de trece pies y medio de largo y un calibre de grueso, cinco pulgadas y ocho líneas, cuatro teleras, un eje, dos ruedas y su avantrén, que solo sirve para conducirle.

Carabinero. Soldado de a caballo, cuya arma principal es la carabina. El de la brigada de carabineros.

Lo es igualmente el soldado elegido en las compañías de a caballo por su buena conducta, valor y experiencia [...].

Caserna. Bóveda que se construye debajo de los baluartes, hecha a prueba de bomba, que sirve para alojar los soldados, almacén de pólvora y otras cosas.

Coracero. Soldado de caballería armado de coraza.

Cestón. Tegido de mimbres o ramas de figura cilíndrica, de cinco o seis pies de alto y cuatro de ancho, el cual Ileno de tierra sirve para cubrirse y defenderse del fuego de los enemigos.

8 Ya ocho páginas atrás Sanz daba cuenta de los cestones /lenos de tierra, que "son los que se ponen sobre el parapeto para hacer fuego al enemigo sin ser visto de él”, acepción de la que Fernández Mancheño, por su parte, decide prescindir, quizá por tratarse de una demasiado contextual. 
Por otro lado, de esta doble forma en Sanz, camisada (en), se pasa al lema simple camisada en Fernández Mancheño, curiosamente la forma que posteriormente desapareció y que, por ejemplo, ya no recoge el Diccionario de autoridades (1990 [1726-1739]).

Finalmente, el afán simplificador de Fernández Mancheño alcanza también a las entradas capellán, centro, complemento, contracola y costado, que equivalen a las más contextuales de Sanz capellán de regimiento, centro de un batallón, complemento de la línea de defensa, contracola de golondrina y costado de fila.

Respecto de las 22 voces de Sanz que Fernández Mancheño desecha, sobresalen, en primer lugar, las referidas a cargos o grados militares exclusivos de Francia, así como a las realidades más estrechamente vinculadas con la historia militar de aquel país, como son las siguientes:

CAPITÁN-TENIENTE, es el comandante de una compañía, guardias de corps o alguna otra tropa de la casa real. Llámanle capitán-teniente porque el mismo rey es el capitán. Los capitanes-tenientes en Francia tienen antigüedad y hacen guardia de primeros coroneles de cavallería y mandan a todos ellos. El título de capitán-teniente no es más antiguo que desde el reynado de Enrique IV, donde se ve por un acto de Luis XIII, de 1615, que Enrique IV instituyó la compañía de gendarmes y que Mons. de Souvre fue el primer capitán-teniente de ella (Sanz, 1749).

CARLOS VII, en la reforma que hizo de milicia francesa, instituyó quince compañías de tropa arreglada y dio título de capitanes a aquellos que las mandavan. Este título ha sido dado poco a poco a todos aquellos que han mandado diversas especies de milicias, tanto en las guardias de los reyes, cavallería ligera, como en la infantería y dragones; preferentemente ay capitanes en todos los cuerpos de tropas. En la milicia francesa havía un capitán general cuya autoridad era la misma que la de capitán general de los exércitos [...] (Sanz, 1749).

COMISSARIO general, es un tercer oficial general de todos los regimientos de cavallería de Francia. Fue creado baxo Luis XIV, en 1654. Mons Esclainviers fue el primero, nombrado por comissión, en 1654, y en empleo en 1656. El comissario general tiene un regimiento baxo el nombre de comissario general (Sanz, 1749).

CONDESTABLE. Al empleo de Gran Senescal de Francia (Justicia General), que fue suprimido en 1191, sucedió el de Condestable, cuya autoridad de aumentó hasta ser el primer empleo de la Corona. Fue instituido por Enrique I en 1060. Empezó desde Alberich de Monmorency y concluyó en el Duque de Lesdeguieres en 1627 baxo Luis XIII (Sanz, 1749).

CROATOS. Son soldados de cavallería en cuerpo de regimiento. El gefe de los croatos de Francia en lugar de tener el título de maestre de campo tiene el de coronel, atribuido a la cavallería extrangera como para hacer conocer que los primeros soldados o gentes de este cuerpo han sido levantados antiguamente en Croacia, provincia sobre la frontera de Ungría. Los croatos son destinados para reconocer al enemigo e insultar su campo o quarteles y a servir de tropa de hostilidad. En un 
día de batalla se les coloca sobre las alas de la primera línea, un poco más apartados que los otros esquadrones y sobre el mismo frente de los dragones (Sanz, 1749).

En este sentido, resultan sumamente reveladoras estas palabras de Fernández Mancheño (1822: VII) de su "Discurso preliminar", con las que advierte que en su diccionario "todo es muy español [...], porque solo he escrito para españoles". Así, no debe resultar extraño que sea precisamente este el conjunto léxico más destacado entre las ausencias detectadas.

En cualquier caso, y aun sin referirse a realidades específicas de Francia, son igualmente desechadas por Fernández Mancheño las entradas de Sanz capitán en segundo9, comisario de víveres ${ }^{10}$ y comisario general de fortificaciones ${ }^{11}$. Ahora bien, en la supresión de esta última, quizá haya jugado un papel determinante la siguiente alusión explícita que, al final de su correspondiente artículo, realiza Sanz a propósito del sueldo general de esta ocupación militar en el país galo: "su sueldo, en Francia, es de treinta mil libras, o bien 120000 reales de vellón cada año” (Sanz, 1749: S.V. comissario general de fortificaciones).

Por otro lado, tanto compañías de ordenanza como cuerpo de guardia avanzada constituyen lemas también descartados por nuestro lexicógrafo del siglo XIX, Ios cuales pertenecen al grupo de los referidos a los distintos roles militares:

COMPAÑÍAS de ordenanza, son las que no entran jamás en cuerpo de regimiento (Sanz, 1749).

CUERPO de guardia abanzada, tanto de cavallería como de infantería, son pequeños cuerpos de tropa apostados a la cabeza de un campo para assegurarle, o sobre las avenidas de una plaza para observar lo que se presenta a la vista. Quando un campo está retrincherado y cubierto por una línea, los cuerpos de guardia de cavallería están fuera de ella y cada quartel tiene su grande y pequeña guardia [...] (Sanz, 1749).

Además, una de las partes de la bayoneta, concretamente su mango, de la que Sanz da cuenta bajo cubo de bayoneta, es asimismo desechada por Fernández Mancheño. Teniendo en cuen-

9 "Es un oficial que por su mérito ha obtenido este empleo, o que su compañía ha sido reformada y sirve en otra" (Sanz, 1749).

10 "El comissario general de víveres tiene baxo su mando otros comissarios, debe saber el número de gente que ha de proveer, escoge lugar propio para formar sus almacenes y hace conducir las municiones para quando la campaña empiece [...]" (Sanz, 1749: S.V. comissario de víveres).

11 "Es su obligación proyectar las plazas y obras nuevas, aprovar o condenar las que han sido proyectadas por otros. El comissario general de fortificaciones visita las plazas del reyno, ordena la reparación de las obras que han sido maltratadas, arregla el trabajo de los ingenieros, a quienes da la orden para el servicio [...]" (Sanz, 1749: S.v. comissario general de fortificaciones). 
ta que la voz que alude a la propia arma, esto es, el hiperónimo bayoneta, sí forma finalmente parte de la macroestructura de su diccionario, la ausencia de este hipónimo tampoco resulta, a nuestro modo de ver, especialmente llamativa. Igualmente, de las cuatro entradas que Sanz consagra al lema cañón, no tiene cabida en la obra de Fernández Mancheño la tercera de ellas, la referida a la equivalencia entre cañón y artillería ${ }^{12}$.

La ausencia de corte de árboles ${ }^{13}$ y cestones llenos de tierra, por su parte, puede deberse al patente carácter enciclopédico imprimido por Sanz a sus artículos lexicográficos.

Son dos, asimismo, los elementos de fortificación definidos por Sanz y desechados, sin embargo, por Fernández Mancheño, a saber, complemento de la cortina y cara de baluarte ${ }^{14}$. En el caso de este segundo, su eliminación parece responder a la preferencia por parte de nuestro lexicógrafo del siglo XIX de su sinónimo frente, lematizado en plural, seguramente porque son dos los frentes o caras de que consta cada uno de los baluartes dentro de una fortificación moderna: "fort. Los lienzos o caras de la muralla que desde los extremos de los flancos se juntan y cerrando el baluarte forman un ángulo” (Fernández Mancheño, 1822: S.v. frentes).

Por su parte, la ausencia de complemento de la cortina resulta más difícil de explicar, aunque, si comparamos su definición con la del lema simple cortina de Fernández Mancheño, no parece descabellado pensar que estemos ante el mismo miembro defensivo y que, como tal, una de sus dos denominaciones sea prescindible:

COMPLEMENTO de la cortina, es lo restante de la cortina ${ }^{15}$ después de haver quitado la distancia desde el ángulo del flanco hasta el ángulo de la gola (Sanz, 1749).

Cortina. fort. El lienzo de muralla que está entre baluarte y baluarte (Fernández Mancheño, 1822).

12 "Se toma también por artillería. Dícese: se les ha tomado el cañón y el bagage a los enemigos" (Sanz, 1749).

13 "Los árboles se cortan en el tiempo que están menos impregnados de humor o que están más enjutos. Los que crecen en el oriente o septentrión son los mejores. Una buena madera tiene la corteza viva y sus hilos derechos. Quando se ha cortado, se dexa fortalecer por espacio de tres meses sin exponerla al sol, porque el viento no le haga abrir o torcer, no obstante, que el abrirse es señal de gran fuerza; después, se corta y limpia, según para el uso que sea, a fin de llevarla a obrar [...]" (Sanz, 1749).

14 "Es la distancia comprehendida desde el ángulo de la espalda hasta el ángulo flanqueado" (Sanz, 1749). "ÁNGULO de la espalda, se forma del flanco y la cara del baluarte" (Sanz, 1749). "ÁNGULO flanqueado, es el concurso de las dos caras de baluarte, que forman su ángulo en medio de ellas" (Sanz, 1749).

15 "CORTINA, es la parte del recinto comprehendida entre dos flancos que están opuestos [...]" (Sanz, 1749). 
En el diccionario militar de Fernández Mancheño, faltan igualmente algunos términos propios de la logística ${ }^{16}$ y la castrametación $n^{17}$. Nos referimos a correría ${ }^{18}$, contribución y campamento ${ }^{19}$. Mientras que nos vemos incapaces de apuntar qué fue lo que llevó a este lexicógrafo a prescindir tanto de correría como de campamento, al no constarnos el abandono por parte de la milicia del siglo XIX de las realidades a las que dichas voces aluden, en el caso de la supresión del lema contribución seguramente contribuyó el excesivo tratamiento enciclopédico al que Sanz le sometió, cuyo resultado fue un artículo de casi cuatro páginas de extensión. Resulta curioso señalar, además, que Sanz se vale precisamente de esta palabra, contribución, en la propia definición de correría, entrada que, como acabamos de comentar, Fernández Mancheño desecha de la macroestructura de su diccionario. Por ello, creemos que no es desacertado emparentar ambas ausencias.

Finalmente, nuestro lexicógrafo del siglo XIX prescinde asimismo de los nombres de dos movimientos tácticos, a saber, conversión ${ }^{20}$ y caraco/21. En lo que respecta al primero, conviene tener en cuenta su largo artículo en el diccionario de Sanz, lo que pudo condicionar su posterior supresión. En cambio, en el caso de caracol seguramente resultó determinante su condición de figura táctica propia de la caballería, orden militar típicamente medieval y, por consiguiente, superado ya en el siglo XIX. De hecho, "ya en los inicios del Renacimiento se hace evidente el progresivo declinar de la caballería en provecho de la infantería, frente a la preponderancia mantenida por la primera durante toda la Edad Media” (Sánchez Orense, 2012: 24). Por otra parte, se constata la eliminación en Fernández Mancheño de la acepción

16 "f. Parte de la organización militar que atiende al movimiento y mantenimiento de las tropas en campaña" (DRAE: S.v. logístico, ca).

17 "f. Arte de ordenar los campamentos militares" (DRAE: S.V. castrametación).

18 "Es la que hace un destacamento de tropa, maltratando un país enemigo, mayormente en las cercanías de una plaza, en que se quiere hacer padecer hambre, o que no quiere pagar las contribuciones" (Sanz, 1749).

19 "Es el alojamiento que se forma con las tiendas a un exército [...]" (Sanz, 1749).

20 "Es un movimiento militar que hace bolver el frente de un batallón a la parte donde estava su flanco. Esto se hace por quartos de conversión, sea a derecha o izquierda. Quando el enemigo quiere atacar uno de los costados, o bien que se le quiere atacar por uno de ellos, para hacer bien este movimiento, es necessario que las hileras y filas no se curben; cada uno deve guardar sus distancias y en los costados del batallón deven estar los más hábiles. Quando se hace un quarto de conversión sobre la derecha, el costado izquierdo marcha y descrive un quarto de círculo sobre el de la derecha, y este deve hacer a la derecha, de suerte que sea como centro o exe sobre el qual se buelvan los demás soldados; al contrario sucede quando se hace el quarto de conversión sobre la izquierda, pues [...]” (Sanz, 1749).

21 "Es un término de guerra, movimiento que hace la cavallería semicircular, o bien media buelta a derecha o izquierda, mudando siempre la figuración a fin que el enemigo esté incierto si le atacara de frente o de costado" (Sanz, 1749). 
de caballero correspondiente a 'soldado de a caballo', si bien el referente se mantiene en su diccionario por medio de la variante cabalero 22.

\section{TABLA 3}

De dos artículos caballero en Sanz a caballero y cabalero en Fernández

\section{SANZ (1749)}

CAVALLERO, o soldado de a cavallo, es un hombre de guerra que sirve y pelea a cavallo. Acostúmbrase decir esta compañía de cavallos es de treinta hombres exclusos los oficiales. CAVALLERO, en término de fortificación es una elevación de tierra cuya massa es redonda, quadrilonga u otra figura, pero la superficie superior siempre es plana, que, guarnecido de un parapeto, cubre los cañones que en él se ponen de batería. Su altura deve ser proporcionada al terreno que le es opuesto de parte del enemigo, pues alguna vez obliga a descubrir para dominar el terreno con ventaja.

Los cavalleros que se construyen en el recinto de una plaza, sean en medio de las cortinas o en la gola de un baluarte, ordinariamente tienen de quince a diez y ocho pies de altura [...].

\section{FERNÁNDEZ MANCHEÑO (1822)}

Caballero. Fuerte que se levanta sobre el terraplén de una plaza de mucha altura, de 80 a 90 pies de largo y de 30 a 40 de ancho; está ceñido de un parapeto, menos por la parte que mira a la ciudad para que en caso de ganarle el enemigo no se pueda sostener en él.

Cabalero. En lo antiguo, soldado de a caballo.

Teniendo en cuenta este ejemplo, podría pensarse que a Fernández Mancheño no le interesaban los nombres de aquellas realidades militares ya superadas en su época, conclusión que, sin embargo, no puede alejarse más de la situación reflejada por su propia obra²3. Efectivamente, ya en su "Discurso preliminar" advertía que había tenido cabida buena parte de la milicia antigua:

He creído muy oportuno consagrar en esta obrita un catálogo de voces propias del arte de la guerra, así científicas como gubernativas y económicas [...], diferentes armas ofensivas y defensivas que ha usado y usa [el ejército español], así como las máquinas de guerra de que se sirvieron los antiguos para los ataques de plazas, y las que sirven en la actualidad (Fernández Mancheño, 1822: V-VI).

Así pues, es con esta declaración de intenciones con la que debe relacionarse, por lo que respecta a la letra $\mathrm{C}$, su decisión de incluir la palabra cíngulo - inexistente en el anterior dic-

22 Entrada que, junto a caballero, forma parte de la macroestructura de numerosos repertorios académicos, desde el siglo XVIII, con el Diccionario de autoridades, hasta el siglo XX, con el DRAE de 1925, el último que lo tiene en cuenta, según datos del NTLLE.

23 Nótese, por ejemplo, que el significado de ‘soldado de a caballo' en realidad no desaparece de su obra, sino que simplemente es recogido bajo un lema un tanto distinto a caballero, concretamente bajo cabalero, la variante más arcaizante. 
cionario de Sanz, dicho sea de paso-, a la que, además, decide acompañar de la abreviatura "ant.", la cual, pese a no hallarse consignada en su previa "Explicación de las abreviaturas usadas en esta obra”24, parece destinar a la rápida detección de objetos militares ya en desuso: “Cíngulo. ant. El cordón que usaban los soldados por insignia” (Fernández Mancheño, 1822).

Ahora bien, a juzgar por los siguientes empleos de esta misma abreviatura, al lexicógrafo decimonónico no solo le interesaron las realidades militares obsoletas, sino también las palabras, nombres o expresiones caídas en desuso:

Cárcava. ant. La zanja o foso hecho para la defensa (Fernández Mancheño, 1822).

Carcavear. ant. Fortificar un campo o ciudad haciendo un foso alrededor (Fernández Mancheño, 1822).

Carnaje. ant. El destrozo o mortandad que resulta en una batalla (Fernández Mancheño, 1822).

Caporal. ant. Lo mismo que cabo de escuadra, que es como hoy se usa (Fernández Mancheño, 1822).

Como es sabido, esta situación léxica o bien es causa o bien tiene como consecuencia la entrada en escena de una determinada equivalencia denominativa, que acabará por imponerse. Así, en lugar de la voz antigua caporal, se empleaba cabo de escuadra, como puede constatarse.

Además de estas, poseen igualmente la condición de anticuadas las entradas calar la visera $^{25}$, camisada ${ }^{26}$, carrera cubierta ${ }^{27}$, casamuro ${ }^{28}$, cerca ${ }^{29}$, certamen ${ }^{30}$ y cierra España ${ }^{31}$, si bien

24 No es "ant." la única abreviatura detectada de la que, a pesar de no incluirse en ese listado inicial, se vale Fernández Mancheño en la práctica para la marcación de determinadas voces. Así, se encuentran igualmente "persp." (perspectiva) en línea vertical, plano geométrico y plano orizontal; "art." y "artill." (artillería) en cerbatana y terciar una pieza; "fisic." (física) en constituir; y "estat." (¿estática?) en funepéndulo, equilibres y plano inclinado. Para más datos al respecto, véase Sánchez Orense (2014: 286). Por otro lado, sobre las marcas, con sus correspondientes abreviaturas, que conforman exactamente aquel inventario, comentaremos algunas cuestiones a continuación.

25 “Voz antigua para dejarla caer sobre la cara” (Fernández Mancheño, 1822).

26 "Voz usada en lo antiguo y que consistía en atacar al enemigo de noche o a la punta del día" (Fernández Mancheño, 1822).

27 "Se llama antiguamente así a lo que hoy galería, y servía en los ataques de las plazas para llegar a cubierto a la muralla” (Fernández Mancheño, 1822).

28 “Antiguamente se llamaba sin terraplén” (Fernández Mancheño, 1822).

29 "Cierta formación antigua de la infantería que equivalía a lo que hoy se llama cuadro o cuadrilongo" (Fernández Mancheño, 1822).

30 "En lo antiguo, duelo, pelea, batalla entre dos o más personas" (Fernández Mancheño, 1822).

31 "Grito o voz militar usada en nuestra milicia antigua con que se animaba a los soldados para que acometiesen con valor al enemigo" (Fernández Mancheño, 1822). 
en estos casos dicha condición no se pone de manifiesto mediante el empleo sistemático de la abreviatura "ant.", sino merced a determinados sintagmas o a las palabras "antiguo" o "antiguamente" insertas en las propias definiciones.

Este mismo procedimiento es seguido también para la marcación de las numerosas realidades - por ejemplo, objetos, instrumentos, armas o grados militares- que, a pesar de estar ya plenamente superadas en la centuria decimonónica, entran a formar parte de la macroestructura de un diccionario publicado entonces, como es el Diccionario militar portátil. De esta forma, la presencia de estas unidades en el repertorio analizado resulta abrumadora. Para dar una idea de la misma, aportamos, a continuación, todas las detectadas bajo la letra C: cabora ${ }^{32}$, cadalso $^{33}$, camelete ${ }^{34}$, camello $^{35}$, partir el campo y el so ${ }^{36}$, can $^{37}$, capacete ${ }^{38}$, capeli$n a^{39}$, capellina ${ }^{40}$, capillo de hierro ${ }^{41}$, carro falcado ${ }^{42}$, casquete ${ }^{43}$, castillo ${ }^{44}$, catapulta ${ }^{45}$, celada ${ }^{46}$,

32 "En lo antiguo era el capitán que mandaba alguna tropa en gefe” (Fernández Mancheño, 1822).

33 "Antigua fortificación o baluarte hecho de madera" (Fernández Mancheño, 1822).

34 "Pieza grande de artillería que se usaba en lo antiguo para batir las murallas" (Fernández Mancheก̃o, 1822).

35 "Otra pieza de la misma arma usada en lo antiguo, muy corta, del calibre de 16 y de muy poco efecto" (Fernández Mancheño, 1822).

36 "En los antiguos duelos era señalar el campo y la luz para que los combatientes no riñesen con ventaja” (Fernández Mancheño, 1822).

37 "Pieza pequeña de bronce en la artillería antigua [...]" (Fernández Mancheño, 1822).

38 "Pieza de la armadura antigua que cubría la cabeza” (Fernández Mancheño, 1822).

39 "Pieza de la armadura antigua que cubría la parte superior de la cabeza" (Fernández Mancheño, 1822).

40 "El soldado de a caballo que usaba de esta armadura” (Fernández Mancheño, 1822).

41 "Pieza de armadura que se usaba antiguamente. Lo mismo que el capacete” (Fernández Mancheño, 1822).

42 "El que tenía fijados en los ejes unas cuchillas fuertes y afiladas para herir al enemigo y guarnecer los costados del ejército. Antiguamente se usaban mucho estos carros" (Fernández Mancheño, 1822).

43 "Pieza de la armadura antigua que cubría y defendía el casco" (Fernández Mancheño, 1822).

44 "Máquina de madera en figura de castillo de que usaban los antiguos y en especialidad las naciones del Oriente en la guerra, el que ponían encima de elefantes, guarnecido de soldados” (Fernández Mancheño, 1822).

45 "Máquina antigua destinada a arrojar piedras y saetas" (Fernández Mancheño, 1822).

46 "Pieza de la armadura antigua que servía para cubrir y defender la cabeza" (Fernández Mancheño, 1822). "Soldado de a caballo que usaba de celada” (Fernández Mancheño, 1822: S.v. id.) 
celada de borgoñesa ${ }^{47}$, centó $n^{48}$, cilicio ${ }^{49}$, cimera ${ }^{50}, \operatorname{coda}^{51}{ }^{51}$, colla ${ }^{52}$, vueltas de corazas ${ }^{53}$, corral $^{54}$, cortao ${ }^{55}$, coselete ${ }^{56}$, cota de armas ${ }^{57}$, crestón ${ }^{58}$, cubo $^{59}$ y cúneo ${ }^{60}$.

Conviene notar que de todas estas voces, tanto de las en sí desusadas como de las referentes a realidades militares ya antiguas, solo hemos hallado en el Diccionario militar de Sanz camisada, por lo que respecta a las primeras, y cimera y cota de armas, en el caso de las segundas:

CAMISADA, (en) ${ }^{61}$ es un ataque que se hacía al enemigo por sorpresa de noche o a la punta del día. Este término ya no está en uso (Sanz, 1749).

47 "Pieza de la armadura antigua que, dejando cubierta la cara, cubría y defendía la parte superior de la cabeza” (Fernández Mancheño, 1822).

48 "En lo antiguo era una especie de manta gruesa con que se cubrían las máquinas de guerra" (Fernández Mancheño, 1822).

49 "Manta de cerdas con que se cubría antiguamente la parte de la muralla que se quería defender" (Fernández Mancheño, 1822).

50 "Adorno que traían antiguamente en el casquete los caballeros, y se formaba de plumas y otras cosas; hoy se ha sustituido con una cola de caballo" (Fernández Mancheño, 1822).

51 "Pieza de la armadura antigua que cubría el codo" (Fernández Mancheño, 1822).

52 "Pieza de la armadura antigua que servía para defender el cuello" (Fernández Mancheño, 1822).

53 "La que daban en lo antiguo los coraceros sobre la derecha. Hoy observan la misma táctica de la caballería de línea” (Fernández Mancheño, 1822).

54 "En la milicia antigua era la formación en figura de cuadro de la guardia del rey en las batallas, muy semejante al cuadro de estos tiempos" (Fernández Mancheño, 1822).

55 "Cierto instrumento antiguo para batir las murallas" (Fernández Mancheño, 1822).

56 "Armadura antigua del cuerpo, compuesta de gola, peto, espaldar, escarcelera, brazaletes y celada" (Fernández Mancheño, 1822). // "El soldado de infantería que en lo antiguo servía en las compañías de arcabuceros y tenía por arma ofensiva una alabarda” (Fernández Mancheño, 1822).

57 "Armadura del cuerpo que se usaba antiguamente. Al principio se fabricaron de cueros retorcidos y anudados, y después de mallas de hierro o alambre gordo. Había algunas que tenían varios adornos y dibujos de oro, plata, colores, etc." (Fernández Mancheño, 1822).

58 "En la armadura antigua es la parte de la celada que se levantaba sobre la cabeza en figura de cresta, en la cual se ponían plumas y otros adornos" (Fernández Mancheño, 1822).

59 "fort. Cualquiera de los torreones de la muralla o fortaleza, redondos, ochavados o cuadrados, que se hacían en las fortalezas antiguas para defender desde ellas la muralla, para lo que hoy sirven los baluartes" (Fernández Mancheño, 1822).

60 "Formación antigua en figura triangular de un batallón que iba a chocar con otro por el vértice para romperle o dividirle" (Fernández Mancheño, 1822).

61 Como ya pusimos de manifiesto, de la doble lematización camisada, en[camisada] de Sanz se pasa al lema simple camisada en Fernández Mancheño, cuya consideración como "voz usada en lo antiguo" seguramente responda a la caída en desuso experimentada en detrimento de su variante encamisada, tal como subyace de la consulta a la tradición lexicográfica española. Por ejemplo, en el Diccionario de autoridades (1990 [1726-1739]) solo se registra encamisada, desechando, así, camisada. 
CIMERA, adorno que traían antiguamente en el casquete los cavalleros; poco tiempo después se descargaron de aquel peso inútil y en su lugar pusieron otro, que solo eran pequeñas figuras y aumentaron muy poco el peso al casquete (Sanz, 1749).

COTA DE ARMAS, este adorno era una especie de túnica sin mangas, semejante, poco más o menos, a las de los diáconos quando ofician. Los franceses tomaron este modo de vestir quando se armaron y se establecieron en los gaulos, pero eran pocos los que podían traher este adorno, solo los príncipes y cavalleros lo trahían [...]. Las cotas de armas eran ordinariamente de telas preciosas, como de tela de oro, de plata, de grana o de martas sevellinas. Los cavalleros afectavan la más magnífica apariencia que les era possible en la cota de armas, fuesse en los torneos o en los exércitos [...]. El uso de las cotas de armas se dexó poco a poco [...] (Sanz, 1749).

Esto es, solo tres de los 41 lemas señalados a propósito de su marcación como "antiguos" o "anticuados" bajo la letra C del Diccionario militar portátil —o bien mediante el recurso a la abreviatura "ant.", o bien a través de contextualizaciones en las propias definiciones - estaban ya presentes en su antecedente más directo, esto es, en el repertorio de Sanz.

De este modo, concluimos que — al menos por lo que respecta a la letra C, si bien, dada la representatividad que le suponemos a la muestra seleccionada, seguramente sea así también para el resto de la obra objeto de estudio - gran parte del nuevo léxico al que da cabida Fernández Mancheño procedería, efectivamente, de épocas de la milicia previas al siglo XIX. Así, de las 659 entradas que bajo la letra C suponen novedades en Fernández Mancheño en contraste con el diccionario de Sanz ${ }^{62}$, ocupa un lugar sumamente destacado el conjunto léxico que acaba de ser desglosado, especialmente el compuesto por las voces que designan partes o elementos de las antiguas armaduras de guerra.

También, el extraordinario aumento del lemario en el repertorio de Fernández Mancheño con respecto al de Sanz puede deberse en parte a casos como el de consejos de guerra (Sanz) frente a consejo de guerra ordinario, consejo de oficiales generales y consejo de guerra verbal (Fernández Mancheño). Mientras que en Sanz toda la información sobre estas realidades militares se halla aglutinada en un único artículo, a saber, en el encabezado por la denominación general consejos de guerra, en Fernández Mancheño, si bien prácticamente se constatan los mismos datos, estos aparecen desglosados en tres lemas ${ }^{63}$.

62 Recuérdese que, bajo esta letra, se contabilizaron, en el caso del Diccionario militar portátil, 703 artículos en el glosario general más los 46 de las "Adiciones" finales, lo que hace un total de 749 entradas en la letra C, de las cuales, como ya especificamos, 90 ya estaban en el Diccionario militar de Sanz, con lo cual la verdadera contribución de Fernández Mancheño a la historia del léxico y la lexicografía militar proviene en realidad de las 659 restantes.

63 Para más ejemplos de este tipo, consúltese Sánchez Orense (2014: 280-281). En cualquier caso, no son tampoco extraños los contraejemplos a esta tendencia de Fernández Mancheño. Así, aunque 
Pero es que, además, simplemente con la revisión de su "Explicación de las abreviaturas usadas en esta obra” rápidamente se advierte que Fernández Mancheño se propuso atender, al margen de los típicamente militares, términos técnicos que en principio parecen un tanto alejados de la temática bélica en la que se hallaba imbuido, lo que lógicamente contribuye también a un mayor volumen en la macroestructura de su diccionario.

\section{IMAGEN 1}

Fernández Mancheño (1822: VIII)

\section{Explicacion de las abreviaturas usa- das en esta obra.}

$\begin{array}{ll}\text { Alg. } & \text { Algebra. } \\ \text { Arit. } & \text { Aritmética. } \\ \text { Ast. } & \text { Astronomia. } \\ \text { Arq. } & \text { Arquitectura. } \\ \text { Fort. } & \text { Fortificacion. } \\ \text { Geom. } & \text { Geometria. } \\ \text { Geog. } & \text { Geografia. } \\ \text { Est. } & \text { Estrategia. } \\ \text { Hid. } & \text { Hidráulica. } \\ \text { Mat. } & \text { Mátemática. } \\ \text { Táct. } & \text { Táctica. } \\ \text { Trig. } & \text { Trigonometria. } \\ \text { Hidrom. } & \text { Hidrometria. }\end{array}$

En este sentido, debe destacarse, en primer lugar, el establecimiento de distintas abreviaturas para cada una de las disciplinas matemáticas existentes, lo que no hace sino demostrar

ciertamente son bastante más numerosos los casos en los que de un artículo de Sanz Fernández Mancheño establece dos o más, apuntamos el siguiente, detectado de nuevo bajo la letra C, donde se constata que los dos artículos de calibre del siglo XVIII se transforman en uno solo en el XIX:

CALIBRE, es la capacidad o abertura de una pieza, o de toda arma de fuego, por donde entra y sale la bala. Llámase en término de artillería el calibre o diámetro de la boca del cañón de toda arma de fuego.

La vara del calibre, llamada vara sphereométrica, sirve para hallar y medir los diámetros o calibres de cañones y morteros proporcionados a las balas y bombas con que se deben cargar. CALIBRE, se dice también al diámetro de las balas de cañón o fusil. Dícese es del mismo calibre quando son proporcionados a las piezas o fusiles que deven servir (Sanz, 1749).

Calibre. Es el diámetro de la bala, bomba o granada.

Lo es igualmente la capacidad o abertura de una pieza o arma de fuego por donde saley entra la bala. Los calibres se miden con la vara llamada spherométrica, que sirve para saber qué cañones o morteros se han menester para tirar las balas o bombas calibradas (Fernández Mancheño, 1822). 
que para nuestro lexicógrafo decimonónico toda la terminología matemática resultaba fundamental en lo concerniente al servicio de las armas ${ }^{64}$. Veamos algunos ejemplos, de nuevo pertenecientes a la letra C:

Cubo. algeb. ${ }^{65}$. La tercera potencia o potestad de una cantidad, o bien el producto del cuadrado multiplicado por la raíz (Fernández Mancheño, 1822).

Cuestión. alg. Problema en que mediante ciertas cantidades conocidas se ha de buscar alguna o algunas incógnitas (Fernández Mancheño, 1822).

Catorce. arit. Número cardinal que se compone de una decena y cuatro unidades; y en caracteres árabes, que son los más usados en el día en Europa, se representa así = 14 (Fernández Mancheño, 1822).

Ciento. arit. Número que vale diez veces diez. Lo mismo que cien (Fernández Mancheño, 1822).

Círculo. geom. Figura plana de una sola línea, llamada circunferencia, que forma un cerco perfectamente redondo y cerrado (Fernández Mancheño, 1822).

Cónico. geom. Lo perteneciente al cono, como superficie cónica, sección cónica, etc., etc. (Fernández Mancheño, 1822).

Componen un importante grupo, asimismo, tanto las voces geográficas como las astronómicas, según ejemplifican cabo, caleta, canal, cerro, citerior, continente y contorno, por citar solo algunos ejemplos de las primeras; y Cáncer, canícula, cardinal, carrera del Sol, carro, Centauro y coluro, como representantes de las segundas.

Para cerrar este apartado consagrado a las cuestiones macroestructurales, nos gustaría apuntar que, si bien a primera vista puede parecer curiosa la selección léxica efectuada por Fernández Mancheño, dicho proceder no dista de su principal propósito divulgativo, a saber, ser capaz de instruir a los futuros militares del Estado, pues, como él mismo especifica abiertamente en su "Discurso preliminar", ninguno "estará más seguro interior y exteriormente que aquel que tuviere un ejército más organizado, más instruido, y más obediente a la voz de los que le mandaren" (Fernández Mancheño, 1822: III-IV). En este sentido, y teniendo en cuenta lo complicado de la profesión de las armas, decide incluir, junto a las propiamente militares, "una porción de otras ciencias, cuya utilidad no podrá menos de conocer el obser-

64 A este respecto, téngase en cuenta que las matemáticas y la enseñanza militar estuvieron fuertemente vinculadas en España durante buena parte del ochocientos, según Sánchez Ron (1992: 67).

65 Nótese que en este caso Fernández Mancheño no emplea la forma fijada en su listado inicial de abreviaturas, "alg.", sino una variante de la misma, "algeb.". No es este el único ejemplo de fluctuación en este sentido. 
vador curioso, y que aunque a primera vista no parezcan propias son de suma importancia, especialmente en tiempo de guerra” (Fernández Mancheño, 1822: VI).

\section{Contenidos microestructurales}

Cuneta. fort. Es una profundidad particular en medio de un foso seco y corre todo lo largo de él; su ancho es de diez y ocho a veinte pies. Sirve para disputar el paso al enemigo y para dar corriente a las aguas Ilovedizas y que no se formen en ellos charcos ni pantanos que se corrompan y puedan perjudicar a la salud (Fernández Mancheño, 1822).

Como se constata en este artículo lexicográfico del Diccionario militar portátil, los elementos microestructurales de los que se sirve su autor, Fernández Mancheño, son más bien escasos: tras el lema se proporciona la indicación del ámbito militar, por medio de las correspondientes abreviaturas, al que este pertenece, y a continuación le sigue la información lexicográfica central, la definición.

Así, el cotejo de dicho artículo con el mismo del Diccionario militar de Sanz revela que, respecto a los contenidos microestructurales, la única novedad en Fernández Mancheño radica en el establecimiento y manejo de un completo sistema de marcación diatécnica:

CUNETA, es una profundidad particular en medio de un fosso seco y corre todo lo largo de él; su ancho es de diez y ocho a veinte pies. Sirve para disputarle el paso al enemigo (Sanz, 1749).

En este sentido, si bien se han detectado ejemplos que evidencian cierta falta de sistematicidad en este aspecto ${ }^{66}$, debe ponerse de relieve el esfuerzo realizado por Fernández Mancheño para la depuración de la técnica lexicográfica ya iniciada por Sanz en el siglo anterior (véase la tabla 4).

Como suele resaltarse, las definiciones suponen el elemento principal de cualquier obra lexicográfica. Ahora bien, dado que el estudio sistemático de todas las definiciones presentes en el Diccionario militar portátil y su comparación con las que en el siglo anterior redactó Raimundo Sanz excedería, con mucho, los límites del presente trabajo, hemos decidido centrarnos en una única cuestión en torno a las mismas: el rastreo de las definiciones de tipo

66 "Alinear. Voz de táctica que consiste en hacer que se coloquen los soldados en una o más filas guardando el contacto de los codos y observando el costado por donde se manda la alineación; en la caballería solo se observa el costado" (Fernández Mancheño, 1822). “Alinearse. táct. Colocarse sobre la nueva línea demarcada por los guías, guiándose por el tacto de codos y observando el costado por donde viene el movimiento, para lo que es necesario inclinar un poco la vista a fin de que quede bien rectificada la línea” (Fernández Mancheño, 1822). 


\section{TABLA 4}

Macho en Sanz y en Fernández Mancheño: de la marcación mediante frase contextual al empleo de una precisa abreviatura

\section{SANZ (1749)}

MACHO, en término de fortificación es un parage retirado en lo más alto de una plaza para capitular más ventajosamente en caso de haverse apoderado el enemigo de parte o de toda la plaza; regularmente llama también última retirada.

enciclopédico, por un lado, y de las lingüísticas, por otro, ya que la determinación del predominio en uno u otro sentido supone un asunto de especial relevancia dentro de los ámbitos especializados.

En esta ocasión, tomamos como muestra representativa los artículos correspondientes a la letra I. En el caso de Fernández Mancheño, de acuerdo con nuestros anteriores cálculos, serían 66 los artículos disponibles, de los cuales 62 pertenecen al glosario propiamente dicho y 4 a las "Adiciones". Por su parte, el Diccionario militar de Raimundo Sanz reúne bajo esta letra un total de 16 artículos. Tras un exhaustivo análisis, podemos afirmar que de las definiciones que acompañan a esos 66 primeros artículos solo 7 poseen características claramente enciclopédicas, a saber, incendiario, infantería, ingeniero, insignias, inspector, intendente de ejército e itinerario, entre las que destaca, por su extensión, la de infantería.

En cambio, la mayoría de las explicaciones procedentes del siglo XVIII son de tipo enciclopédico, pues, de las 16 mencionadas, hasta 10 responden a esta modalidad, mientras que las únicas entradas que pueden citarse como portadoras de definiciones estrictamente lingüísticas son idrographía, indulto, incommensurable, incomunicable, inaccesible e inexpugnable.

No obstante, lo más Ilamativo de este cotejo es que hasta 4 de los 7 términos que Fernández Mancheño define de forma enciclopédica se encontraban ya en el primer diccionario militar del español: infantería, ingeniero, inspector e intendente. Es decir, además de que la presencia del enciclopedismo es mucho mayor en la obra de Sanz, al menos en lo que respecta a la letra I, parece evidente su influencia en las escasas ocasiones en las que Fernández Mancheño se decanta por esta tipología definitoria.

Si bien somos conscientes de lo reducido de la muestra seleccionada, la confrontación de otros artículos coincidentes, como son cañón y zapa, cuya filiación se hace rápidamente evidente, nos lleva a creer en lo extensible de esta conclusión a todo el Diccionario militar portátil, objeto de la presente investigación. 
De todas formas, no conviene olvidar las numerosas ocasiones en las que largas explicaciones de Sanz son considerablemente reducidas por Fernández Mancheño, como sucede, entre otras, en salida, socorrer, subsistencia y trompeta. Sobre este aspecto resultan reveladoras las intenciones de nuestro lexicógrafo, expuestas en su "Discurso preliminar", a propósito de la presencia del adjetivo portátil en el título de su diccionario: "he procurado adoptar la más posible concisión, abrazando al mismo tiempo dos extremos; el primero, el poco coste y evitar lo superfluo; y el segundo, que sea portátil sin incomodidad esencial” (Fernández Mancheño, 1822: VI-VII).

Mención aparte merece el artículo sitio, ya que, a pesar de ser sumamente dilatado (alcanza algo más de seis columnas o unas tres páginas), Fernández Mancheño, consciente de esta situación, trata de justificarse y limitar sus palabras lo máximo posible, según señala en el segundo párrafo de este vasto artículo: "varios han sido los modos con que se han expugnado las plazas sitiadas, pero, como un diccionario se debe limitar solo a la manifestación o significación de las voces, me ceñiré únicamente a demostrar como de paso los arbitrios e invenciones que los hombres han usado en las edades antigua, media y presente" (Fernández Mancheño, 1822: S.v. sitio).

Y a pesar de su amplitud, si tenemos en cuenta que la microestructura de sitio alcanza unas 18 páginas en Sanz, en cierto modo sí lo consigue.

También, por citar un último ejemplo, en el artículo encabezado por la entrada situación de plazas fortificadas, claro reflejo del artículo situación en Sanz ${ }^{67}$, Fernández Mancheño muestra su inquietud por traspasar los estrictos límites de los diccionarios de lengua: "diferentes son las situaciones de las plazas de guerra y, aunque esta obra no es un arte de hacerla, daré una sucinta idea a mis lectores de las situaciones, ventajas y defectos de las plazas, aunque abuse de su paciencia y exceda de los límites de diccionario" (Fernández Mancheño, 1822: s.v. situación de plazas fortificadas).

\section{Conclusiones}

La realización del presente trabajo emana de nuestro pleno convencimiento acerca de la trascendencia de los diccionarios, inigualables testimonios de la riqueza léxica de cada idioma y, como tal, fundamentales para los estudios lexicológicos. A ello se añade, en este caso concreto, la constatación de la falta de trabajos sobre el Diccionario militar portátil, el primero plenamente original en lengua española.

67 Eso sí, Fernández Mancheño decide desglosar en varios artículos la abundante información aportada por Sanz bajo este único lema. Para más detalles, véase Sánchez Orense (2014: 280-281). 
Dada la abundante información que atesora, su estudio puede versar sobre diversas cuestiones y abordarse, además, desde diferentes puntos de vista. En esta ocasión decidimos centrarnos en la búsqueda de similitudes o discrepancias con respecto a su antecesor más directo, el Diccionario militar de Sanz, para lo que se han atendido de modo preferente una serie de aspectos macroestructurales y, aunque de forma menos exhaustiva, igualmente otros microestructurales, lo que, si bien en este segundo caso no nos permite extraer datos concluyentes, sí que nos alienta a seguir investigando al respecto.

En lo que respecta a los primeros, recalcamos la importancia que en el Diccionario militar portátil adquiere el acervo léxico militar, al testimoniar en múltiples artículos lexicográficos tanto la desaparición de voces como de las realidades con ellas referidas, lo que lo convierte en un instrumento esencial para el estudio de la milicia antigua y su terminología.

Es más, la innovación en el caso de Fernández Mancheño respecto a su inmediato predecesor, el Diccionario militar de Sanz, consiste en recurrir a la terminología bélica de épocas pasadas. Buena parte de las nuevas incorporaciones detectadas en la macroestructura del Diccionario militar portátil no procede de términos recientemente incorporados por la milicia del siglo XIX, sino de aquellos ya en desuso, sustituidos por otros, o bien que aluden a realidades militares en franco declive frente a las nuevas costumbres. De hecho, entre las 659 entradas que bajo la letra C suponen novedades en Fernández Mancheño, sobresalen especialmente las que designan partes o elementos de las antiguas armaduras de guerra.

Asimismo, creemos haber puesto de manifiesto que numerosos lemas de carácter novedoso en el repertorio de Fernández Mancheño se adscriben a otras disciplinas científicas (geografía, astronomía o matemáticas), cuya controvertida presencia en un diccionario militar es defendida en el "Discurso preliminar": "en ninguna otra corporación necesitan los hombres de más estudio, de más pundonor, ni de más aplicación que en la carrera de las armas, y ninguna reúne tantas complicaciones ni ciencias como las que necesita el que ha de mandar" (Fernández Mancheño, 1822: IV).

Por otra parte, a propósito de los contenidos microestructurales del Diccionario militar portátil, destacamos dos cuestiones. La primera, concerniente a la marcación: merced a ella, Fernández Mancheño realiza un notable avance respecto a Sanz. La segunda, respecto a las definiciones empleadas, y es que se percibe — al menos en la pequeña muestra analizada, la conformada por los artículos de la letra I- la superación del marcado enciclopedismo al que se adscribe el repertorio de Sanz. A pesar de ello, también se han detectado varios casos, fuera de dicha letra, en los que Fernández Mancheño se vale de explicaciones poco lingüísticas, si bien, consciente de ello, suele preocuparse por justificar su modo de proceder. En este sentido, para poder obtener conclusiones más determinantes al respecto, se impone como necesario, en futuros trabajos, ampliar el número de artículos objeto de estudio, de tal forma que se pueda dictaminar con mayor seguridad hasta qué punto Fernández Mancheño realmente 
rompe con el enciclopedismo de Sanz, investigación en la que resultaría interesante añadir además el análisis de posteriores representantes de la lexicografía militar, de tal forma que el panorama sobre las definiciones enciclopédicas en esta modalidad lexicográfica quedara totalmente esbozado.

En definitiva, esperamos que el presente trabajo sirva para dar a conocer el Diccionario militar portátil y animar, así, a la apertura de nuevas líneas de investigación en torno al mismo, las cuales, sin duda, resultarán de enorme interés para los estudios lexicológicos y lexicográficos.

\section{Bibliografía citada}

AlmiRANTE, José, 2002 [1869]: Diccionario militar, Madrid: Ministerio de Defensa.

CASTAÑón, Luis, 1791-1792: Encyclopedia metódica, Madrid: Imprenta de Sancha.

CoRsInI, Luis, 1849: Vocabulario militar, Madrid: Imprenta del Semanario e Ilustración.

Estévanez, Nicolás, 1897: Diccionario militar con un vocabulario español-francés-alemán, París: Garnier Hermanos.

Fernández Mancheño, José, 1822: Diccionario militar portátil, o recopilación alfabética de todos los términos propios de las ciencias militares, explicación de los empleos de la milicia y sus obligaciones [...], Madrid: Imprenta de Miguel de Burgos.

Gago-Jover, Francisco, 2008: "Glosarios y diccionarios militares del siglo XIX" en Dolores Azorín: El diccionario como puente entre las lenguas y culturas del mundo. Actas del II Congreso Internacional de Lexicografía Hispánica, Alicante: Universidad de Alicante-Fundación Biblioteca Virtual Miguel de Cervantes, 670-677.

Gago-Jover, Francisco, 2011: "Catálogo descriptivo de la lexicografía militar española anterior a la Primera Guerra Mundial”, Revista de Lexicografía 17, 33-63.

Gago-Jover, Francisco, y Fernando Tejedo Herrero, 2007: “Introducción” en Raimundo Sanz: Diccionario militar, edición y estudio de Francisco Gago Jover y Fernando Tejedo Herrero, Zaragoza: Institución "Fernando el Católico”, VII-XXI.

HeviA, Deogracias, 1857: Diccionario general militar de voces antiguas y modernas, Madrid: Imprenta y estereotipia de M. Rivadeneyra.

MoretTI, Federico, 1828: Diccionario militar español-francés, Madrid: Imprenta Real.

Pinto CebriÁn, Fernando, 2013: Ejército e historia. El pensamiento profesional militar español a través de la literatura castrense decimonónica, Madrid: Ministerio de Defensa. 
Real Academia Española, 1990 [1726-39]: Diccionario de autoridades, Gredos: Madrid.

Real Academia Española, 2001: Nuevo tesoro lexicográfico de la lengua española (edición DVD), Madrid: Espasa Calpe. (NTLLE).

Real Academia Española, 2014: Diccionario de la lengua española, vigesimotercera edición, BarceIona: Espasa Libros (DRAE).

Rubió y Bellvé, Mariano, 1895-1901: Diccionario de ciencias militares, Barcelona: Administración de la Revista científico-militar y Biblioteca militar.

Sánchez Orense, Marta, 2012: La fortificación y el arte militar en los tratados renacentistas en lengua castellana: estudio lexicológico y lexicográfico, Salamanca: Ediciones Universidad de Salamanca, Colección Vítor, 322.

Sánchez Orense, Marta, 2013: "El Diccionario militar (1749) de Raimundo Sanz y la incorporación de galicismos al castellano”, Anuari de Filologia. Estudis de Lingüística 3, 159-183.

Sánchez Orense, Marta, 2014: "El Diccionario militar portátil (1822) de Fernández Mancheño: análisis metalexicográfico y macroestructural", Cuadernos del Instituto Historia de la Lengua 9, 273-294.

SÁnchez Orense, Marta, 2015: "Un ejemplo de la corriente traductora en la lexicografía especializada: el Diccionario militar (1749) de Raimundo Sanz" en Julia Pinilla y Brigitte Lépinette (eds.): Traducción y difusión de la ciencia y la técnica en España (siglos XIV-XIX), Valencia: Publicacions de la Universitat de València, 403-423.

SÁnchez Ron, José Manuel, 1992: "Las ciencias físico-matemáticas en la España del siglo XIX”, Ayer 7, 51-84.

Sanz, Raimundo, 1749: Diccionario militar, o recolección alfabética de todos los términos propios al arte de la guerra [...], Barcelona: Imprenta de Juan Piferrer.

WiLlson, James, 1794: A pocket vocabulary in six languages, viz. English, German, Dutch, French, Italian and Spanish; containing such words, terms and questions, as are most generally in use, particularly in military service, Londres: R. Hindmarsh. 